\title{
sciendo
}

\section{Influence of the Varied Pitch Shape on Soccer Players Physiological Responses and Time-Motion Characteristics During Small-Sided Games}

\author{
by \\ David Casamichana ${ }^{1}$, Paul S Bradley², Julen Castellano
}

The aim of this study was to investigate the effect of pitch shape modifications on heart rate responses and time-motion characteristics in soccer players during 5-a-side small-sided games (SSGs). Players completed four different SSG dimensions: (1) short narrow pitch $(S N ; 40 \times 25 \mathrm{~m})$, (2) short wide pitch $(S W ; 66 \times 25 \mathrm{~m})$, (3) long narrow pitch $(L N ; 40 \times 50 \mathrm{~m})$, and (4) long wide pitch $(L W ; 66 \times 50 \mathrm{~m})$. Twenty amateur soccer players (age: $21 \pm 5 \mathrm{yr}$; stature: $176.8 \pm 1.9 \mathrm{~cm}$; body mass: $72.7 \pm 3.7 \mathrm{~kg}$ ) were monitored using a heart rate monitor and a $10 \mathrm{~Hz}$ GPS device. Mean maximum heart rate $\left(\% H R_{\max }\right)$, rating of perceived exertion (RPE), peak running speed, total distance covered $(T D)$, distance covered in four speed categories, number of moderate and high accelerations (Ac), decelerations $(D c)$, changes of direction (COD) and player load were recorded. Increasing the pitch length had a greater effect compared to increasing the pitch width especially on $R P E(3.8,6.3,4.9$ and $6.6 \mathrm{AU}$ to $S N, L N, S W$ and $L W$, respectively) and timemotion characteristics such as TD $\left(101,127,108\right.$ and $131 \mathrm{~m} \cdot \mathrm{min}^{-1}$ to $S N, L N, S W$ and $L W$, respectively), peak speed $\left(4.8,6.1,5.2\right.$ and $6.2 \mathrm{~m} \cdot \mathrm{s}^{-1}$ to $S N, L N, S W$ and $L W$, respectively), and the number of accelerations, decelerations, and changes of direction. The data demonstrates that increasing the length rather than the width of 5-a-side SSG has a greater impact on players' responses in terms of increasing workloads.

Key words: soccer, specific training, GPS, heart rate, pitch dimensions.

\section{Introduction}

Small-sided games (SSGs) are now a common feature of soccer training (Ford et al., 2010) as they enable a greater understanding of which indices impact players' responses (Ade et al., 2014). The SSG playing area is a structural element that is modified most frequently when planning training drills. Typical modifications include variations in the length and width of the pitch and the relative space per player (Casamichana and Castellano, 2010) or maintaining the same pitch dimension but dividing it into different areas (Gonçalves et al., 2017). Varying pitch dimensions has been a focus of previous research (Hill-Haas et al., 2011) given that it can modify the demands placed on players. Researchers have primarily focused on the size of the playing area (Casamichana and Castellano, 2010; Castellano et al., 2015; Hodgson et al., 2014; Kelly and Drust, 2009; Owen et al., 2004; Rampinini et al., 2007; Tessitore et al., 2006) with or without goals (Castellano et al., 2013d). The rationale for this is clear as both variables have been found to affect the physical and technical demands placed on players (Casamichana and Castellano, 2010) and interactive team behavior (Frencken et al., 2013).

Nevertheless, studies demonstrate contradictory findings regarding players'

\footnotetext{
1 - Faculty of Physiotherapy and Speech Therapy Gimbernat-Cantabria University School associated with the University of Cantabria (UC). Torrelavega, Spain.

2 - Research Institute of Sport E Exercise Sciences, Liverpool John Moores University, Liverpool, UK.

3 - Faculty of Education and Sport. University of the Basque Country (UPV/EHU). Vitoria-Gasteiz, Spain.
} 
responses to different SSG pitch dimensions. While some studies have found that SSGs played in large areas result in greater workloads (Aroso et al., 2004; Casamichana and Castellano, 2010; Hodgson et al., 2016; Rampinini et al., 2007; Owen et al., 2004; Williams and Owen, 2007), others either found similar results for smaller pitches (Tessitore et al., 2006) or reported no differences at all (Kelly and Drust, 2009). The inconsistency reported for various SSG pitch dimensions means that a greater understanding is needed of how these metrics impact players physiological responses and time-motion characteristics (Stone and Kilding, 2009). Variations in the number of players per team (Rampinini et al., 2007) or the presence of goalkeepers (Castellano et al., 2013d) could be behind these inconsistencies. Typically, small pitch dimensions result in more accelerations-decelerations (Castellano et al., 2015; Hodgson et al., 2016) and less distance covered at high speed (Casamichana and Castellano, 2010).

When designing soccer drills, the pitch area can be modified by changing its length (distance between the goals) or its width (distance between the two side lines). Nevertheless the decision to change the width or the length of the pitch, should be made using systematic and scientific reasoning. Usually coaches change the two dimensions at the same time in order to replicate a competitive pitches length:width ratio (higher length than width). But in regular soccer matches, teams tend to play wider than longer (Castellano et al., 2013a) and this spatial distribution changes during competitive matches (Castellano et al., 2013b). Therefore, it could be interesting to propose a task in the field where the distance between the targets is shorter than the distance between side lines. However, limited data exist on how changing just the distance between the goal without changing dimensions of the field affects players' responses.

Most studies have examined pitch dimension modifications while keeping the ratio between length and width constant. Nevertheless, there is a lack of knowledge on the effect of variation in the shape of the field manipulating just the width or the length, keeping constant the other one. The shapes of the fields used in the previously described works proposed greater lengths (distance between goals) than widths (distance between side lines), with the length:width ratio always above 1 (longed fields instead of flattened ones). These ratios range from 1.2:1 to 1.5:1 in most studies (Hill-Hass et al., 2011). However, there is no evidence on the physical and physiological demands when the pitch is wider than longer (length:width ratio is less than 1).

Thus, this study investigated the effect of pitch shape modifications on heart rate responses and time-motion characteristics in soccer players during 5-a-side SSGs (plus goalkeepers). The findings will help coaches and physical trainers to prescribe SSGs in a more systematic manner, taking into account how the shape of the playing field influences the players' responses.

\section{Methods}

\section{Participants}

Twenty male amateur soccer players (age: $21 \pm 5$ yr; stature: $176.8 \pm 1.9 \mathrm{~cm}$; body mass: $72.7 \pm$ $3.7 \mathrm{~kg}$; Yo-Yo intermittent recovery test 1 (Yo-Yo IRT1): $2256 \pm 298 \mathrm{~m}$ ) from the same regional level team participated in the study. They had played federation soccer for an average of $11 \mathrm{yr}$ prior to the study. Standard training involved three sessions per week (each lasting $\sim 90 \mathrm{~min}$ ) and a weekly league match. All players were informed of the research design, as well as the potential benefits and risks, and written consent was obtained prior to participation. Ethical approval was granted by an Institutional Human Research Ethics Committee.

\section{Measures}

Physiological responses

Physiological responses were assessed using internal training load measures such as heart rate and RPE. Heart rates were recorded every $5 \mathrm{~s}$ using a telemetric device (Polar Team Sport System, Polar Electro, Oy, Finland). Maximum heart rate $\left(\mathrm{HR}_{\max }\right)$ was determined for each player by means of the Yo-Yo IRT1 (Bangsbo et al., 2008) and heart rate responses were expressed as mean values of a percentage of the individual maximum heart rate (\%HRmax). To assess RPE (Foster, 1998), each player was asked to complete the Borg 10-point Category Ratio (CR10) scale at the end of each SSG (Fanchini et al., 2015).

Time-Motion Characteristics

Time-motion characteristics were measured using portable global positioning 
system devices operating at $10 \mathrm{~Hz}$ (GPS, MinimaxX v.4.0, Catapult, Australia). Once recorded, data was analyzed using proprietary software (Catapult Sprint v.5.1.0, Catapult, Australia). The following were recorded: total distance covered per minute (TD), peak speed (maximum speed reached by each player), triaxial accelerometer data (player load; PL), distance covered in five speed categories, and the number of accelerations, decelerations, and changes of direction in two acceleration categories. Similarly to previous studies, five speed categories were used for analysis: 0-6.9, 7.0-12.9, 13.0-17.9, 18.0-20.9 and >21.0 $\mathrm{km} \cdot \mathrm{h}^{-1}$ (Hill-Haas et al., 2009; Impellizzeri et al., 2009). Accelerations, decelerations, and changes of direction were categorized as moderate or high using the respective values of $>3 \mathrm{~m} \cdot \mathrm{s}^{-2}$ and $>4 \mathrm{~m} \cdot \mathrm{s}^{-2}$ (Akenhead et al., 2013; Davies et al., 2013). These methods had previously been determined as reliable and valid for monitoring high-intensity activities in soccer (Castellano et al., 2011; Varley et al., 2012).

\section{Procedures}

The study variables were the pitch length and width. Players completed four different SSG shapes: (1) short narrow pitch (SN; $40 \times 25 \mathrm{~m})$, (2) short wide pitch (SW; $66 \times 25 \mathrm{~m})$, (3) long narrow pitch (LN; $40 \times 50 \mathrm{~m}$ ), and (4) long wide pitch $(\mathrm{LW} ; 66 \times 50 \mathrm{~m})$. The results of the SSGs played on the long and short pitches (SN vs LN and SW vs LW) were used to investigate the impact of pitch length modifications on players' responses. Likewise, the results of the SSGs played on the narrow and wide pitches (SN vs SW and LN vs LW) were used to study the impact of changes to pitch width. With exception of the offside rule, standard eleven-a-side soccer rules were followed.

The study was conducted under similar environmental conditions across a two-week period in May (2012-13 season). In the weeks leading up to the study, the players were familiarized with the various SSG design and micro technologies. In the week immediately before the study, each player performed the YoYo Intermittent Recovery Test level 1 (Yo-Yo IRT1) to determine the maximum heart rate (HRmax; Krustrup et al., 2003). The test was performed on the same day on an outdoor artificial pitch with all players wearing boots.
Two training sessions, separated by a week, were held on an outdoor artificial pitch at similar times of the day $(8: 30 \mathrm{pm})$ to avoid the effects of circadian variations on performance (Drust et al., 2005). Each session started with a 15min warm-up followed by four six-min SSGs, with a passive recovery period of eight min between games to prevent fatigue. The games involved the same number of players (five per side plus goalkeepers), but were played on different sized pitches. The order of the SSG was as follows: SN, SW, LN and LW (Table 1). Whilst the distance between goals was always greater than the distance between the side lines in league matches, three of the pitches designed for this study were wider than they were long because players tended to occupy the width of the pitch more often than the length during match-play (Castellano et al., 2013a). Ten players plus two goalkeepers participated in both sessions. Goalkeepers were not monitored. There were no substitutions, but the 10 outfield players who participated in the second session were different to those who participated in the first session. Accordingly, 20 recordings were made for each SSG (excluding goalkeepers), resulting in a total of 80 recordings.

To avoid potential imbalances and ensure equality between the two teams, players were classified and grouped according to the following variables: min of competitive play, performance on the Yo-Yo IRT1, playing position, and a subjective appraisal from the coach (Casamichana and Castellano, 2010). Coaches were present during all SSGs to offer encouragement to the players (Rampinini et al., 2007). In addition, eight balls were distributed around the edge of the pitch to maximize effective playing time (Casamichana and Castellano, 2010). Players were advised to maintain their normal nutritional and fluid intake during the study period.

\section{Statistical Analyses}

Data are presented as means \pm standard deviations. A paired-sample $\mathrm{t}$ test with $\mathrm{a}$ significance level of $p \leq .05$ was used for all comparisons. Effect Sizes (ES) were computed using a Cohen D calculation to determine the magnitude of the difference between the SSGs. The descriptive terms associated with ES were trivial (0.0-0.19), small (0.2-0.59), moderate (0.6$1.19)$, large (1.2-1.9), and very large $(>2.0)$ 
(Batterham and Hopkins, 2006; Hopkins et al., 2009). A magnitude-based inference approach was also adopted to assess differences between SSGs using the following qualitative probabilities: almost certainly not $(<1 \%)$, very unlikely $(<5 \%)$; unlikely/probably not $(<25 \%)$, possibly/possibly not $(25-75 \%)$, likely/probably $(>75 \%)$, very likely $(>95 \%)$, and almost certainly $(>99 \%)$. A significant effect was set at $>99 \%$ and a substantial effect at $>75 \%$ (Aughey, 2011; Suarez-Arrones et al., 2013; Maszczyk et al., 2014).

\section{Results}

Time-motion characteristics and the physiological responses to changes in pitch length are shown in Table 2. From the qualitative assessment, there were almost certain differences for RPE, TD, peak speed and PL when pitch width was changed from narrow to wide. The differences observed for the heart rate were almost certainly in the narrow SSGs and likely in the wide SSGs. Additionally, substantial differences were found for moderate and high accelerations and for high decelerations in the narrow SSGs, while the frequency of decelerations decreased when the length of the pitch was increased. In the wide SSGs, there was a significantly higher frequency of moderateintensity COD on the short pitch as well as a higher frequency of high-intensity decelerations.

Table 3 shows the responses for changes in SSG pitch width. Comparisons were made between the two short pitches (SN vs SW) and the two long pitches (LN vs LW), separately. Differences in long pitch SSGs were found only for the number of moderate-intensity COD, while in the short pitch, differences were found for RPE, moderate decelerations, TD, and peak speed. Substantial differences were detected for PL and high-intensity COD.

Figure 2 shows the distances covered in the different speed categories for each of the SSGs. An increase in pitch width was shown to influence physical loads, with an increase in the distance covered on the shortest pitches in the range $<7.0 \mathrm{~km} \cdot \mathrm{h}^{-1}(299 \pm 22$ vs $285 \pm 36 \mathrm{~m}$; ES $=0.66$ \pm 0.42 ), yet on the longest pitches the value ranged between 7.0 and $12.9 \mathrm{~km} \cdot \mathrm{h}^{-1}$ (263 \pm 55 vs $290 \pm 66$ $\mathrm{m} ; \mathrm{ES}=0.43 \pm 0.30), 13.0$ and $17.9 \mathrm{~km} \cdot \mathrm{h}^{-1}(48 \pm 27$ vs $69 \pm 33 \mathrm{~m}$; ES $=0.57 \pm 0.36)$ and 18 and 20.9 $\mathrm{km} \cdot \mathrm{h}^{-1}(27 \pm 18$ vs $36 \pm 16 \mathrm{~m}$; ES $=0.44 \pm 0.31)$.

Table 1

Permutations of small-sided games in relation to width and length

\begin{tabular}{llllllll}
\hline Week & Session & Rep & Teams & Format & Width & Length & $\begin{array}{l}\text { Surface } \\
\text { Area/ player }\end{array}$ \\
\hline & 1 & 1 & A vs B & SN & $40 \mathrm{~m}$ & $25 \mathrm{~m}$ & $100 \mathrm{~m}^{2}$ \\
1 & 1 & 2 & A vs B & SW & $66 \mathrm{~m}$ & $25 \mathrm{~m}$ & $165 \mathrm{~m}^{2}$ \\
& 1 & 3 & A vs B & LN & $40 \mathrm{~m}$ & $50 \mathrm{~m}$ & $200 \mathrm{~m}^{2}$ \\
& 1 & 4 & A vs B & LW & $66 \mathrm{~m}$ & $50 \mathrm{~m}$ & $330 \mathrm{~m}^{2}$ \\
\hline & 1 & C vs D & SN & $40 \mathrm{~m}$ & $25 \mathrm{~m}$ & $100 \mathrm{~m}^{2}$ \\
& 2 & 2 & C vs D & SW & $66 \mathrm{~m}$ & $25 \mathrm{~m}$ & $165 \mathrm{~m}^{2}$ \\
& 2 & 3 & C vs D & LN & $40 \mathrm{~m}$ & $50 \mathrm{~m}$ & $200 \mathrm{~m}^{2}$ \\
& 2 & 4 & C vs D & LW & $66 \mathrm{~m}$ & $50 \mathrm{~m}$ & $330 \mathrm{~m}^{2}$ \\
\hline
\end{tabular}

Rep - repetition; SN - short narrow; SW - short wide; LN - long narrow; LW - long wide. 
Table 2

Physiological responses and time-motion characteristics to changes in pitch length during small-sided games.

\begin{tabular}{|c|c|c|c|c|c|}
\hline Variable & SN & $\mathbf{L N}$ & Dif & $\mathrm{ES} \pm 90 \% \mathrm{CL}$ & $\begin{array}{l}\text { Qualitative } \\
\text { Assessment }\end{array}$ \\
\hline$\% \mathrm{HR}_{\max }(\%)$ & $83.4 \pm 5.1$ & $87.7 \pm 4.0$ & $5 \%$ & $0.81 \pm 0.22$ & Almost certainly \\
\hline RPE (AU) & $3.8 \pm 1.5$ & $6.3 \pm 1.4$ & $66 \%$ & $1.34 \pm 0.43$ & Almost certainly \\
\hline $\mathrm{TD}\left(\mathrm{m} \cdot \mathrm{min}^{-1}\right)$ & $101.2 \pm 11.8$ & $126.6 \pm 13.4$ & $25 \%$ & $1.78 \pm 0.20$ & Almost certainly \\
\hline Peak speed $\left(\mathrm{m} \cdot \mathrm{s}^{-1}\right)$ & $4.8 \pm 0.4$ & $6.1 \pm 0.6$ & $27 \%$ & $2.67 \pm 0.61$ & Almost certainly \\
\hline Player load (AU) & $75.0 \pm 13.2$ & $85.1 \pm 12.5$ & $14 \%$ & $0.70 \pm 0.15$ & Almost certainly \\
\hline Moderate accelerations (n) & $1.8 \pm 1.7$ & $1.9 \pm 1.9$ & $6 \%$ & $0.12 \pm 0.47$ & Unclear \\
\hline High accelerations (n) & $2.0 \pm 1.6$ & $1.2 \pm 1.0$ & $-40 \%$ & $0.68 \pm 0.74$ & Likely \\
\hline Moderate decelerations (n) & $3.3 \pm 2.5$ & $2.7 \pm 1.4$ & $-18 \%$ & $0.44 \pm 0.48$ & Likely \\
\hline High decelerations (n) & $1.15 \pm 1.6$ & $0.7 \pm 0.8$ & $-39 \%$ & $0.66 \pm 0.91$ & Likely \\
\hline Moderate-intensity COD (n) & $8.6 \pm 4.6$ & $6.9 \pm 2.4$ & $-20 \%$ & $0.29 \pm 0.39$ & Unclear \\
\hline High-intensity COD (n) & $3.0 \pm 2.3$ & $2.4 \pm 1.5$ & $-20 \%$ & $0.33 \pm 0.50$ & Unclear \\
\hline Variable & SW & LW & Dif & $\mathrm{ES} \pm 90 \% \mathrm{CL}$ & $\begin{array}{l}\text { Qualitative } \\
\text { Assessment }\end{array}$ \\
\hline$\% \mathrm{HR}_{\max }(\%)$ & $84.3 \pm 4.8$ & $86.5 \pm 4.5$ & $3 \%$ & $0.43 \pm 0.30$ & Likely \\
\hline RPE (AU) & $4.9 \pm 1.0$ & $6.6 \pm 1.2$ & $35 \%$ & $1.26 \pm 0.51$ & Almost certainly \\
\hline $\mathrm{TD}\left(\mathrm{m} \cdot \mathrm{min}^{-1}\right)$ & $107.7 \pm 12.8$ & $131.4 \pm 14.4$ & $22 \%$ & $1.60 \pm 0.31$ & Almost certainly \\
\hline Peak speed $\left(\mathrm{m} \cdot \mathrm{s}^{-1}\right)$ & $5.2 \pm 0.7$ & $6.2 \pm 0.6$ & $19 \%$ & $1.30 \pm 0.54$ & Almost certainly \\
\hline Player load (AU) & $78.8 \pm 12.9$ & $86.2 \pm 14.7$ & $9 \%$ & $0.53 \pm 0.29$ & Very likely \\
\hline Moderate accelerations (n) & $2.0 \pm 1.6$ & $1.4 \pm 1.3$ & $-30 \%$ & $0.05 \pm 0.70$ & Unclear \\
\hline High accelerations (n) & $1.7 \pm 1.5$ & $0.9 \pm 1.1$ & $-47 \%$ & $0.26 \pm 0.64$ & Unclear \\
\hline Moderate decelerations (n) & $1.8 \pm 1.3$ & $1.4 \pm 1.4$ & $-22 \%$ & $0.03 \pm 0.54$ & Unclear \\
\hline High decelerations (n) & $1.5 \pm 1.0$ & $0.4 \pm 0.6$ & $-73 \%$ & $0.76 \pm 0.78$ & Likely \\
\hline Moderate-intensity COD (n) & $7.3 \pm 3.9$ & $4.5 \pm 2.1$ & $-38 \%$ & $0.66 \pm 0.40$ & Very likely \\
\hline High-intensity COD (n) & $2.0 \pm 1.1$ & $1.8 \pm 1.6$ & $-10 \%$ & $0.14 \pm 0.48$ & Unclear \\
\hline
\end{tabular}

\section{$C L$ - confidence level; Dif-difference; $E S$ - effect size; $A U$ - arbitrary units;}

$T D$, total distance covered per minute: $n$ - frequency; $S N$ - short narrow; $S W$ - short wide;

$L N$ - long narrow; $L W$ - long wide.
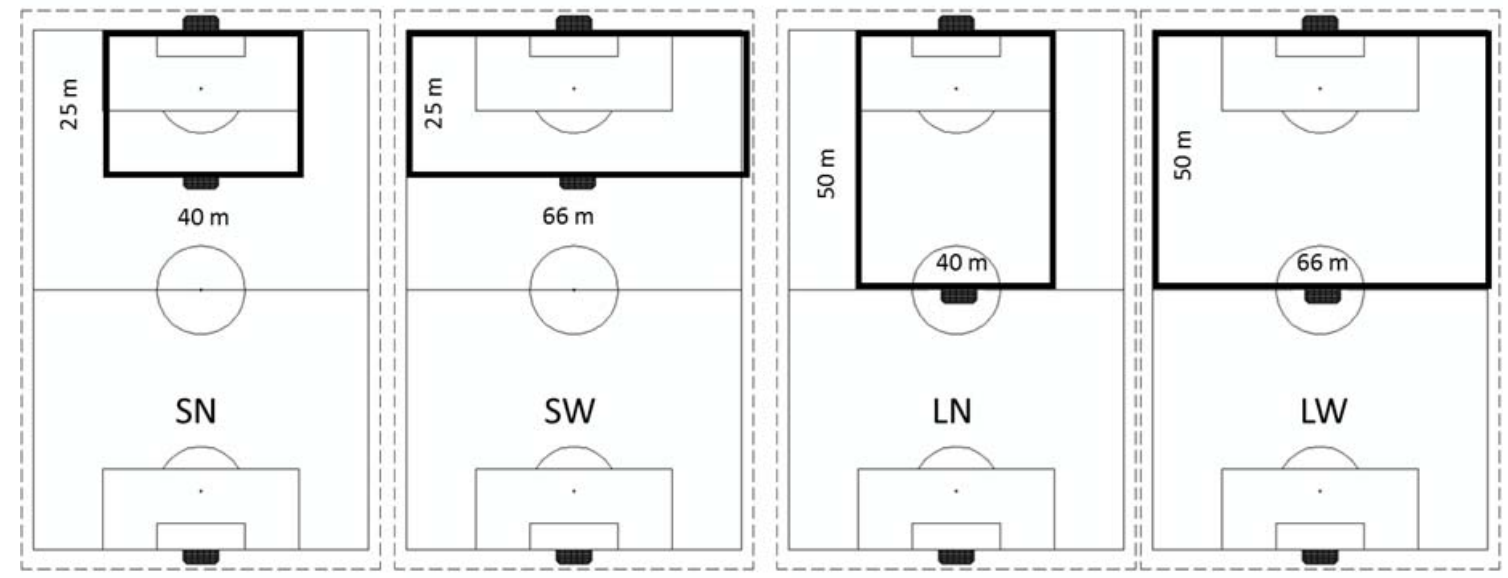

Figure 1

Dimensions for each small-sided game format. SN indicates short narrow, SW is short wide,

$L N$ is long narrow and LW is long wide. 
Table 3

Physiological responses and time-motion characteristics to changes in pitch width during SSGs.

\begin{tabular}{|c|c|c|c|c|c|}
\hline Variable & SN & SW & Dif & $\mathrm{ES} \pm 90 \% \mathrm{CL}$ & $\begin{array}{l}\text { Qualitative } \\
\text { Assessment }\end{array}$ \\
\hline$\% \mathrm{HR}_{\max }(\%)$ & $83.4 \pm 5.1$ & $84.3 \pm 4.8$ & $1 \%$ & $0.18 \pm 0.23$ & Unclear \\
\hline RPE (AU) & $3.8 \pm 1.5$ & $4.9 \pm 1.0$ & $29 \%$ & $0.76 \pm 0.36$ & Almost certainly \\
\hline $\mathrm{TD}\left(\mathrm{m} \cdot \mathrm{min}^{-1}\right)$ & $101.2 \pm 11.8$ & $107.7 \pm 12.8$ & $6 \%$ & $0.49 \pm 0.26$ & Very likely \\
\hline Peak speed $\left(\mathrm{m} \cdot \mathrm{s}^{-1}\right)$ & $4.8 \pm 0.4$ & $5.2 \pm 0.7$ & $8 \%$ & $1.02 \pm 0.69$ & Very Likely \\
\hline Player load (AU) & $75.0 \pm 13.2$ & $78.8 \pm 12.9$ & $5 \%$ & $0.28 \pm 0.16$ & Likely \\
\hline Moderate accelerations (n) & $1.8 \pm 1.7$ & $2.0 \pm 1.6$ & $11 \%$ & $0.01 \pm 0.55$ & Unclear \\
\hline High accelerations (n) & $2.0 \pm 1.6$ & $1.7 \pm 1.5$ & $-15 \%$ & $0.12 \pm 0.60$ & Unclear \\
\hline Moderate decelerations (n) & $3.3 \pm 2.5$ & $1.8 \pm 1.3$ & $-45 \%$ & $1.07 \pm 0.43$ & Almost certainly \\
\hline High decelerations (n) & $1.15 \pm 1.6$ & $1.5 \pm 1.0$ & $30 \%$ & $0.24 \pm 0.78$ & Unclear \\
\hline Moderate-intensity COD (n) & $8.6 \pm 4.6$ & $7.3 \pm 3.9$ & $-15 \%$ & $0.37 \pm 0.45$ & Unclear \\
\hline High-intensity COD (n) & $3.0 \pm 2.3$ & $2.0 \pm 1.1$ & $-33 \%$ & $0.61 \pm 0.58$ & Likely \\
\hline Variable & $\mathbf{L N}$ & $\mathbf{L W}$ & Dif & $\mathrm{ES} \pm 90 \% \mathrm{CL}$ & $\begin{array}{l}\text { Qualitative } \\
\text { Assessment }\end{array}$ \\
\hline$\% \mathrm{HR}_{\max }(\%)$ & $87.7 \pm 4.0$ & $86.5 \pm 4.5$ & $-1 \%$ & $0.43 \pm 0.30$ & Unclear \\
\hline RPE (AU) & $6.3 \pm 1.4$ & $6.6 \pm 1.2$ & $5 \%$ & $0.21 \pm 0.43$ & Unclear \\
\hline $\mathrm{TD}\left(\mathrm{m} \cdot \mathrm{min}^{-1}\right)$ & $126.6 \pm 13.4$ & $131.4 \pm 14.4$ & $4 \%$ & $0.30 \pm 0.25$ & Unclear \\
\hline Peak speed $\left(\mathrm{m} \cdot \mathrm{s}^{-1}\right)$ & $6.1 \pm 0.6$ & $6.2 \pm 0.6$ & $2 \%$ & $0.20 \pm 0.28$ & Unclear \\
\hline Player load (AU) & $85.1 \pm 12.5$ & $86.2 \pm 14.7$ & $1 \%$ & $0.06 \pm 0.21$ & Unlikely \\
\hline Moderate accelerations (n) & $1.9 \pm 1.9$ & $1.4 \pm 1.3$ & $-26 \%$ & $0.02 \pm 0.65$ & Unclear \\
\hline High accelerations (n) & $1.2 \pm 1.0$ & $0.9 \pm 1.1$ & $-25 \%$ & $0.00 \pm 0.60$ & Unclear \\
\hline Moderate decelerations (n) & $2.7 \pm 1.4$ & $1.4 \pm 1.4$ & $-48 \%$ & $0.38 \pm 0.68$ & Unclear \\
\hline High decelerations (n) & $0.7 \pm 0.8$ & $0.4 \pm 0.6$ & $-43 \%$ & $0.29 \pm 0.61$ & Unclear \\
\hline Moderate-intensity COD (n) & $6.9 \pm 2.4$ & $4.5 \pm 2.1$ & $-35 \%$ & $0.72 \pm 0.28$ & Almost certainly \\
\hline High-intensity COD (n) & $2.4 \pm 1.5$ & $1.8 \pm 1.6$ & $-25 \%$ & $0.14 \pm 0.48$ & Unclear \\
\hline
\end{tabular}

$$
C L \text { confidence level; Dif-difference; ES - effect size; } A U \text { - arbitrary units; }
$$

$T D$ - total distance covered per minute: $n$ - frequency; $S N$ - short narrow; $S W$ - short wide; $L N$ - long narrow; $L W$ - long wide.

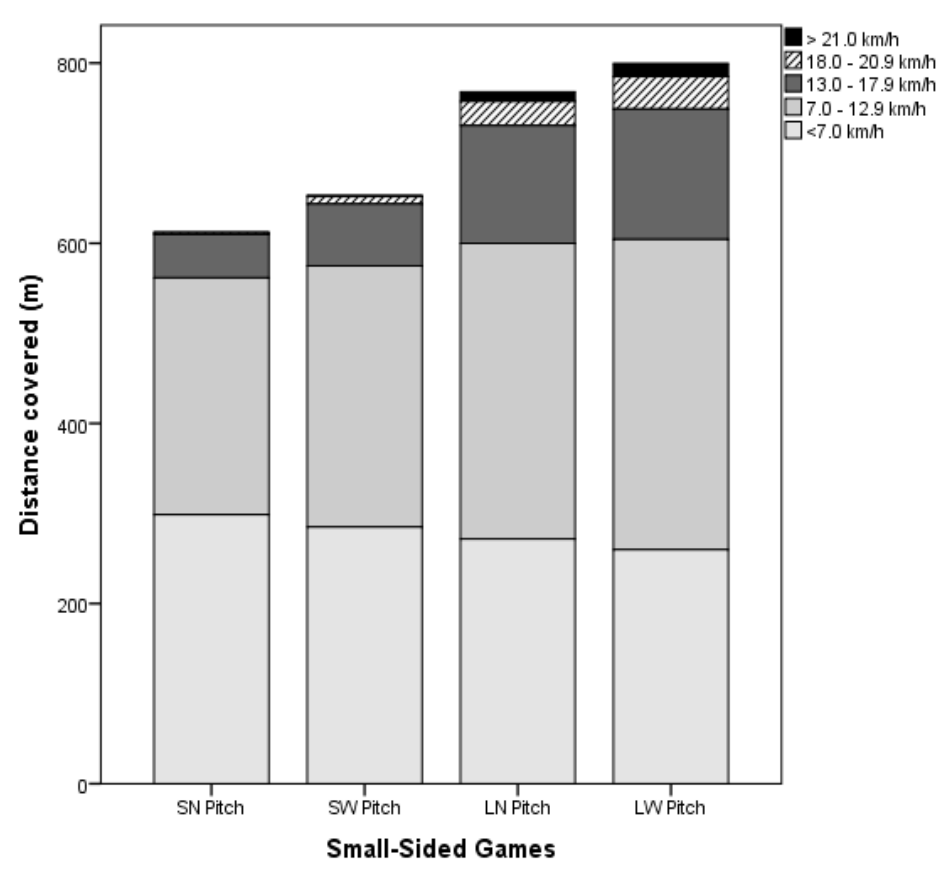

Figure 2

Distance covered in different speed categories for each small-sided game format. SN indicates short narrow, $S W$ is short wide, $L N$ is long narrow and $L W$ is long wide. 
Increasing pitch length revealed a significant increase in the distance covered on the narrow pitch $<7.0 \mathrm{~km} \cdot \mathrm{h}^{-1}(299 \pm 22$ vs $272 \pm 42 \mathrm{~m}$; ES $=0.63$ $\pm 0.25), 7.0-12.9 \mathrm{~km} \cdot \mathrm{h}^{-1}(263 \pm 55 \mathrm{vs} 329 \pm 65 \mathrm{~m}$; ES $=1.24 \pm 0.28), 13.0-17.9 \mathrm{~km} \cdot \mathrm{h}^{-1}(48 \pm 27$ vs $131 \pm 39$ $\mathrm{m} ; \mathrm{ES}=3.4 \pm 0.70)$ and $18.0-21.0 \mathrm{~km} \cdot \mathrm{h}^{-1}(2 \pm 4 \mathrm{vs}$ $27 \pm 18 \mathrm{~m}$; ES $=2.8 \pm 1.12$ ). On the wide pitch, differences were observed for the distance covered $<7.0 \mathrm{~km} \cdot \mathrm{h}^{-1}(285 \pm 36$ vs $260 \pm 24 \mathrm{~m}$; ES = $0.92 \pm 0.64)$ and $7.0-12.9 \mathrm{~km} \cdot \mathrm{h}^{-1}(290 \pm 66 \mathrm{vs} 345 \pm$ $69 \mathrm{~m}$; ES $=0.84 \pm 0.47$ ), and also for $13.0-17.9$ $\mathrm{km} \cdot \mathrm{h}^{-1}(69 \pm 33$ vs $145 \pm 41 \mathrm{~m} ; \mathrm{ES}=1.32 \pm 0.34)$ and $18.0-21.0 \mathrm{~km} \cdot \mathrm{h}^{-1}(8 \pm 8$ vs $36 \pm 16 \mathrm{~m}$; ES $=1.76 \pm$ $0.54)$.

\section{Discussion}

This study examined the influence of separately modifying the width and the length of a SSG pitch on physiological and time-motion characteristics of soccer players. Although studies have demonstrated that increasing the total surface area of a pitch increases the physiological demands (Aroso et al., 2004; Casamichana and Castellano, 2010; Owen et al., 2004; Rampinini et al., 2007; Williams and Owen, 2007), it is not known whether modifying just one dimension (width or length) has the same effect. The main finding from the present study is that modifying length places greater physiological demands on players than modifying width. It would therefore appear that distance between goals has a greater impact on physiological loads than distance between the side lines. However, not all load indicators move in the same direction, highlighting the need to study how different variables respond during the monitoring of training sessions (Casamichana et al., 2013). The principal application of this research is that all formats of SSG had high cardiovascular demands, but coaches wishing to focus on neuromuscular responses associated with accelerations, decelerations, and changes of direction should design SSGs to be played on short pitches, whereas those wishing to work on high-speed movements should design SSGs on larger pitches, giving priority to length rather than width for the same playing surface.

In the present study, physiological responses varied minimally and we only observed differences between SN and LN (5\% increase in $\% \mathrm{HR}_{\max }$ ). The \%HRmax values observed in all four
SSGs (range, 83-87\%) were consistent with rates reported by other studies of SSGs in soccer (Brandes et al., 2011; Hill-Haas et al., 2009). The SSG format also appears to be an effective means of improving endurance in soccer players (Dellal et al., 2008; Rampinini et al., 2007).

In the present study, similar variations were observed for the distance covered, peak speed, and player loads, with increases seen for all variables in SSGs played on the longer pitches. However, when the width of the pitch was increased, an increase in physical demands placed on players was only observed on the short pitch. One possible explanation for these results is that goal-scoring situations are more common in SSGs (Casamichana and Castellano, 2010), meaning that players are predominantly located in the centre of the playing area, leaving the wide areas free. This is a similar situation to that seen in goal areas during competitive matches (Castellano et al., 2013a). It is also important to note that our results may have been influenced by the fact that the increase in the length of the pitch accounted for a $100 \%$ increase (from 25 to $50 \mathrm{~m}$ ), while that of the width accounted for an increase of just $60 \%$ (from 40 to $66 \mathrm{~m}$ ). The findings of our study appear to support the theory that players' loads are strongly impacted by the vertical component due to strikes in running (Davies et al., 2013), while 2D players' loads may be a better reflection of agility demands (Davies et al., 2013).

Using a longer pitch increased distances covered in the different speed categories, regardless of width. The distance covered increased in all speed categories for games played on the narrow pitches and increased substantially in all categories on the wide pitches. However, the distance covered was higher in the stop-walk category in games played on short pitches than in those played on long pitches, regardless of width. With respect to the increase in width, a substantial increase in distance covered was observed in the lower speed categories $(-5 \%$ for stop-walk category, $9 \%$ for the $7.0-12.9 \mathrm{~km} \cdot \mathrm{h}^{-1}$ category and $31 \%$ for $13.0-17.9 \mathrm{~km} \cdot \mathrm{h}^{-1}$ category) for the games played on the short pitch. For the long pitch, a substantial difference $(35 \%)$ was seen only in the 18-20.9 $\mathrm{km} \cdot \mathrm{h}^{-1}$ category. Perhaps doubling the length of the narrow pitch (from $40 \times 25 \mathrm{~m}$, i.e. 100 $\mathrm{m}^{2}$ per player to $40 \times 50 \mathrm{~m}$, i.e. $165 \mathrm{~m}^{2}$ per player) was sufficient to increase physical demands. 
However, increasing the width of the long pitch from $40 \times 50 \mathrm{~m}\left(200 \mathrm{~m}^{2}\right.$ per player $)$ to $66 \times 50 \mathrm{~m}$ $\left(330 \mathrm{~m}^{2}\right.$ per player) resulted in hardly any changes in players' responses, possibly because the members of both attacking and defending teams tended to cluster closer together in the central areas in search of a goal opportunity (Castellano et al., 2013a).

Analysing the frequency of accelerations of different intensity during training could provide information on neuromuscular training responses (Osgnach et al., 2010). Indeed, accelerations are an increasing focus of research in both competitive soccer games and training sessions (Akenhead et al., 2013; Castellano and Casamichana, 2013). The present results seem to indicate that increasing the length of narrow pitches leads to a substantial reduction in the frequency of high accelerations (2.0 vs 1.2 ; $\mathrm{ES}=$ $0.7)$, high decelerations (1.15 vs $0.7 ; \mathrm{ES}=0.7)$ and moderate accelerations ( 3.3 vs 2.7 ; ES $=0.4$ ), In contrast, the present study only observed a substantial reduction in the number of high accelerations (1.5 vs 0.4 ; ES $=0.8$ ) when the length of the narrow pitch was increased. In SSGs on short pitches, where players are closer to both their opponents and to the goal, there are more actions leading up to a shot (Casamichana and Castellano, 2010), possibly explaining the higher frequency of accelerations. Another possible explanation for the higher number of accelerations on short narrow pitches is related to the density of players relative to the surface area of the pitch $\left(100 \mathrm{~m}^{2}\right.$ in $\mathrm{SN}$ and $200 \mathrm{~m}^{2}$ in the $\left.\mathrm{LN}\right)$. In other words, in higher density situations, players would be required to make more agility maneuvers (Davies et al., 2013) due to the proximity of their opponents. This is also relevant to match play with central players in the English Premier League producing shorter high-intensity and sprinting bouts than wide players due to great player density in central regions (Bush et al., 2015).

Some of the principal limitations of our study were that the order of the SSGs was not randomized. Although players were accustomed to this quantity and type of SSGs, fatigue could have affected the players' responses. To avoid this situation, a recovery period of $8 \mathrm{~min}$ was included in the study. Previous studies suggest recovery times $>4$ min do not impact the physical and physiological demands of multiple SSGs (Köklü et al., 2015). Finally, this study fails to provide information on the technical and tactical demands, which would have provided additional insight into strategic behavior during various SSGs (Casamichana and Castellano, 2010; Castellano et al., 2016, 2017).

Interestingly, width does not appear to alter the frequency of accelerations or decelerations, as we only found differences for moderate decelerations, which decreased when the width of the short pitch $(25 \mathrm{~m})$ was changed from 40 to $66 \mathrm{~m}$. Thus, coaches wishing to increase accelerations should focus on SSGs played on short pitches. These results confirm the finding of Castellano and Casamichana (2013) that different-intensity accelerations were more common in SSGs than in friendly soccer matches.

\section{References}

Ade J, Harley J, Bradley PS. The physiological response, time-motion characteristics and reproducibility of various speed endurance drills in elite youth soccer players: small sided games vs generic running. Int J Sports Physiol Perform, 2014; 9: 471-479

Akenhead R, Hayes P, Thompson K, French D. Diminutions of acceleration and deceleration output during professional football match play. J Sci Med Sport, 2013; 16(6): 556-561

Aroso J, Rebelo N, Gomes-Pereira J. Physiological impact of selected game related exercises. J Sports Sci, 2004; 22(6): 522

Aughey RJ. Increased high-intensity activity in elite Australian football finals matches. Int J Sports Physiol Perform, 2011; 6(3): 367-379

Bangsbo J, Laia FM, Krustrup P. The Yo-Yo Intermittent Recovery Test: A Useful Tool for Evaluation of Physical Performance in Intermittent Sports. Sports Med, 2008; 38(1): 37-51

Batterham AM, Hopkins WG. Making meaningful inferences about magnitudes. Int J Sports Physiol Perform, 
2006; 1(1): 50-57

Brandes M, Heitmann A, Müller L. Physical responses of different small-sided game formats in elite youth soccer players. J Strength Cond Res, 2011; 26: 1353-1360

Bush M, Barnes C, Hogg B, Archer D, Bradley PS. Evolution of Match Performance Parameters for Various Playing Positions in the English Premier League. Hum Movement Sci, 2015; 39: 1-11

Casamichana D, Castellano J. Time-motion heart rate perceptual and motor behaviour demands in smallsides soccer games: Effects of pitch size. J Sports Sci, 2010; 28(14): 1615-23

Casamichana D, Castellano J, Calleja-González J, San Román J, Castagna C. Relationship between indicators of training load in soccer players. J Strength Cond Res, 2013; 27(2): 269-374

Castellano J, Álvarez D, Blanco-Villaseñor A. Analyzing the space for interaction in soccer. Rev Psi Deporte, 2013a; 22(2): 437-446

Castellano J, Álvarez-Pastor D, Figueira B, Coutinho D, Sampaio J. Identifying the effects from the quality of opposition in a Football team positioning strategy. I J Perform Ana Sport, 2013b; 13(3): 822-832

Castellano J, Casamichana D. Differences in the number of accelerations between small-sided games and friendly matches in soccer. J Sports Sci Med, 2013c; 12: 209-210

Castellano J, Casamichana D, Calleja-González J, Román JS, Ostojic SM. Reliability and Accuracy of $10 \mathrm{~Hz}$ GPS Devices for Short-Distance Exercise. J Sports Sci Med, 2011; 10: 233-4

Castellano J, Casamichana D, Dellal A. Influence of game format and number of players on heart rate responses and physical demands in small-sided soccer games. J Strength Cond Res, 2013d; 27(5): 12951303

Castellano J, Fernández E, Echeazarra I, Barreira D, Garganta J. Influence of pitch length on inter- and intrateam behaviors in youth soccer. Anales psic, 2017; 33(3): 486-496

Castellano J, Puente A, Casamichana D, Etxeazarra I. Influence of the number of players and the relative pitch area per player on heart rate and physical demands in youth soccer. J Strength Cond Res, 2015; 29(6): 1683-1691

Castellano J, Silva P, Usabiaga O, Barreira D. The influence of scoring targets and outer-floaters on attacking and defending team dispersion, shape and creation of space during small-sided soccer games. J Hum Kinet, 2016: 51, 153-163

Davies M, Young W, Farrow D, Bahnert A. Comparison of agility demands of small-sided games in elite Australian football. Int J Sports Physiol Perform, 2013; 8: 139-147

Dellal A, Chamari K, Pintus A, Girard O, Cotte T, Keller D. Heart rate responses during small-sided games and short intermittent running training in elite soccer players: a comparative study. J Strength Cond Res, 2008; 22: 1449-1457

Drust B, Waterhouse J, Atkinson G, Edwards B, Reilly T. Circadian rhythms in sports performance--an update. Chronobiology international, 2005; 22(1): 21-44

Fanchini M, Ghielmetti R, Coutts AJ, Schena F, Impellizzeri FM. Effect of training-session intensity distribution on session rating of perceived exertion in soccer players. Int J Sports Physiol Perform, 2015; 10(4): 426-30

Ford PR, Yates I, Williams AM. An analysis of practice activities and instructional behaviours used by youth soccer coaches during practice: exploring the link between science and application. J Sports Sci, 2010; 28(5): 483-495

Foster C. Monitoring training in athletes with reference to overtraining syndrome. Med Sci Sports Exerc, 1998; 30(7): 1164-1168

Frencken W, Van der Plaats J, Visscher C, Lemmink K. Size matters: Pitch dimensions constrain interactive team behaviour in soccer. J Syst Sci Complex, 2013; 26(1): 85-93

Gonçalves B, Esteves P, Folgado H, Ric A, Torrents C, Sampaio J. Effects of pitch area-restrictions on tactical behavior, physical and physiological performances in soccer large-sided games. J Strength Cond Res, 2017; 31(9): 2398-2408

Hill-Haas S, Dawson B, Coutts A, Rowsell, G. Physiological responses and time-motion characteristics of various small-sided soccer games in youth players. J Sports Sci, 2009; 27: 1-8

Hill-Haas S, Dawson B, Impellizzeri FM, Coutts A. Physiology of small sided games training in football. A 
systematic review. Sports Med, 2011; 41(3): 199-200

Hodgson C, Akenhead R, Thomas K. Time-motion analysis of acceleration demands of 4v4 small-sided soccer games played on different pitch sizes. Hum Mov Sci, 2014; 33: 25-32

Hopkins WG, Marshall SW, Batterham AM, Hanin J. Progressive statistics for studies in sports medicine and exercise science. Med Sci Sports Exerc, 2009; 41: 3-13

Impellizzeri FM, Marcora SM, Castagna C, Reilly T, Sassi A, Iaia FM, Rampinini E. Physiological and performance effects of generic versus specific aerobic training in soccer players. Int J Sports Med, 2006; 27(6): 483-92

Kelly DM, Drust B. The effect of pitch dimensions on heart rate responses and technical demands of smallsided soccer games in elite players. J Sci Med Sport, 2009; 12(4): 475-479

Köklü Y, Alemdaroğlu U, Dellal A, Wong DP. Effect of different recovery durations between bouts in 3-aside games on youth soccer players' physiological responses and technical activities. J Sports Med Phys Fitness, 2015; 55(5): 430-8

Krustrup P, Mohr M, Amstrup T, Rysgaard T, Johansen J, Pedersen P, Bangsbo J. The Yo-Yo intermittent recovery test: physiological response, reliability, and validity. Med Sci Sports Exerc, 2003; 35(4): 697-705

Maszczyk A, Gołaś A, Pietraszewski P, Roczniok R, Zając A, Stanula A. Application of Neural and Regression Models in Sports Results Prediction. Procedia - Soci Behavio Sci, 2014; 117: 482-487

Osgnach C, Poser S, Bernardini R, Rinaldo R, di Prampero PE. Energy cost and metabolic power in elite soccer: a new match analysis approach. Med Sci Sports Exerc, 2010; 42(1): 170-178

Owen A, Twist C, Ford F. Small-sided games: the physiological and technical effect of altering pitch size and player numbers. Insight, 2004; 7(2): 50-53

Rampinini E, Impellizzeri F, Castagna C, Abt G, Chamari K, Sassi A, Marcora SM. Factors influencing physiological responses to small-sided soccer games. J Sports Sci, 2007; 25: 659-666

Stone M, Kilding A. Aerobic conditioning for team sport athletes. Sports Med, 2009; 39(8): 615-642

Suarez-Arrones L, Núñez J, Munguía-Izquierdo D, Portillo J, Mendez-Villanueva A. Impact of Several Matches Within a Day on Physical Performance in Rugby Sevens Referees. Int J Sports Physiol Perform, 2013; 8: 496-501

Tessitore A, Meeusen R, Piacentini M, Demarie S, Capranica L. Physiological and technical aspects of "6-aside" soccer drills. J Sports Med Phys Fitness, 2006; 46(1): 36-43

Varley MC, Fairweather IH, Aughey RJ. Validity and reliability of GPS for measuring instantaneous velocity during acceleration, deceleration, and constant motion. J Sports Sci, 2012; 30: 121-127

Williams K, Owen A. The impact of players numbers on the physiological responses to small sided games. $J$ Sports Sci Med, 2007; 6(Supl.10): 100

\section{Corresponding author:}

\section{Julen Castellano Paulis}

Department of Physical Education and Sport

Faculty of Education and Sport University of the Basque Country (UPV/EHU)

Portal de Lasarte 71

01007 Vitoria-Gasteiz (Spain)

Phone: +34 945013525

Fax: +34 945013501

Email: julen.castellano@ehu.es 